\title{
EQUALITY ON HIS TERMS: \\ DOING AND UNDOING GENDER THROUGH MEN'S DISCUSSION GROUPS ${ }^{1}$
}

\author{
RACHAEL S. PIEROTTI
}

The World Bank, USA

MILLI LAKE

London School of Economics, United Kingdom

\section{CHLOÉ LEWIS}

University of Oxford, United Kingdom

Efforts to promote gender equality often encourage changes to interpersonal interactions as a way of undermining gender hierarchy. Such programs are premised on the idea that the gender system can be "undone" when individuals behave in ways that challenge prevailing gender norms. However, scholars know little about whether and under what conditions real changes to the gender system can result from changed behaviors (Deutsch 2007; Risman 2009). We use the context of a gender sensitization program in the Democratic Republic of Congo to examine prospects for transformative change at the interactional level of the gender system. Over nine months, we observed significant changes in men's quotidian practices. Further, we identified a new commitment among many men to a more equal division of household labor. However, participants consistently undermined the transformative potential of these behavioral changes through their dedication to maintaining control over the objective, process, and meaning of change, resisting conceptions of equality that challenged the gender system. Because quotidian changes left gender hierarchy intact, they appear unlikely to destabilize the logics that legitimate women's subordination.

Keywords: Doing gender, Gender relations, Social change, Household division of labor, Gender equality

\footnotetext{
${ }^{1}$ The published version of this article is as follows:

Pierotti, Rachael S., Milli Lake, and Chloé Lewis. Equality on His Terms: Doing and Undoing Gender Through Men's Discussion Groups. Gender \& Society (Vol 32 No. 4) pp. 540-562.

DOI: 10.1177/0891243218779779 Accepted version shared by permission of SAGE Publications.
} 
AUTHOR'S NOTE: This research was made possible through the generous financial support of the State and Peacebuilding Fund and the Nordic Trust Fund at the World Bank, as well as the World Bank's Umbrella Facility for Gender Equality. The study benefited from close collaboration with the International Rescue Committee (IRC), especially the research team and the Women's Protection and Empowerment Technical Unit. The research would not have been possible without the work of Alfred Banga, Jean de Dieu Hategekimana, and Ghislain Cimanuka. Thank you also to Julia Vaillant, Ruti Levtov, Michelle Poulin, and Nadine Rudahindwa, and to the anonymous reviewers who provided thoughtful comments. All errors are our own. 


\section{INTRODUCTION}

Scholars know little about whether and under what conditions real changes to the gender system can result from changes in individual behaviors (Deutsch 2007; Risman 2009). While recognizing the importance of institutional structures and material inequalities, sociologists also call attention to the role of interaction in challenging, or reproducing the gender system (Ridgeway 2009). Some see the potential for undermining the overarching gender system through individual behavioral change. Others, however, have observed that even interactions that appear gender non-conforming typically serve to reproduce existing hierarchies.

We use the context of a gender sensitization and intimate partner violence prevention program in eastern Democratic Republic of Congo (DRC) to examine prospects for transformative change at the interactional level of the gender system. The program provides an illuminating example of encouraging individuals to "undo gender" through social interactions (Deutsch 2007). Historically, programs in low-income countries aiming to promote gender equality concentrated efforts on empowering women. Over the last decade, however, advocates have turned their attention toward engaging men and boys in these efforts, promoting changes in their behaviors, and challenging beliefs that justify inequality (Barker et al. 2010). The program examined here sought to increase gender equality and men's accountability to women in their community by, inter alia, promoting a more equal division of labor in the household, improving intra-household relationship quality, reducing intimate partner violence, and questioning existing gender norms. The program, operationalized through discussion groups, offered an opportunity to explore the potential for changes at the interactional level of the gender system to effect more systemic change.

Examining the relationship between behavioral and systemic change necessitated close scrutiny of participants' own understandings of the changes they were encouraged to enact in their 
quotidian practices, meaning their routinized and normalized daily behaviors. We draw from a wealth of qualitative data collected over a period of nine months in eastern DRC. The first phase of the research included more than 100 interviews conducted across 14 communities before the beginning of the program. In the second phase, we studied six communities throughout program implementation using ethnographic research, observation of group discussions, targeted interviews, and carefully selected individual case studies. We found program participants generally willing to perform some tasks usually undertaken by women. However, while changes in the daily division of labor served to counter entrenched beliefs about who should do what within a household, men remained wedded to maintaining control over the changes they undertook, undermining the transformative potential of those interactions to contribute toward "undoing" gender.

This case study illuminates potential roadblocks to undoing gender through behavior change. Gender scholars have suggested a theory of change where shifting gender norms follow from gender non-conforming behavior. When women and men behave in ways that minimize gender differences, this can undermine the ideas that legitimate the hierarchy (Deutsch 2007). We show that behavior that reduces the appearance of gender difference in the division of daily tasks alone does not necessarily undermine gender hierarchy. In this case, the trajectory of change was interrupted by men's deliberate attempts to reaffirm gender norms that support the hierarchy. The interactional level may be a site of change to the gender system. However, when those in positions of relative advantage - in this case, men - retain control over the interactional change, they limit the scope for "undoing gender" by inhibiting normative shifts and protecting their position of privilege. 


\section{UNDOING GENDER THROUGH INTERACTION}

Existing literature is inconclusive as to whether real changes in the gender system can result from changes at the interactional level (Ridgeway and Correll 2004; Risman 2004). There is broad agreement that gender is constructed through everyday actions in which men and women perform gender identities through references to dominant socio-cultural scripts (Butler 1990). There is disagreement, however, about the consequences of performing gender in ways that do not conform with social expectations. On the one hand, many empirical studies document that behavior that is inconsistent with prevailing gender norms risks social sanctions, and is often accompanied by the reproduction - and, subsequently, the re-entrenchment - of gender differences (Ridgeway and Correll 2004; Ridgeway 2009). On the other hand, theories of change assert that gender nonconforming behavior can challenge gender norms and lead to gradual changes in the multilevel social structure (Chafetz 1990; Sullivan 2004; Risman 2009).

An important element of each of these perspectives is the interplay between gendered behaviors and the gender norms that legitimate them. Gender norms are the informal rules that serve as guides for behavior and standards against which behaviors are evaluated. The effects of gender norms are largely unconscious; individuals do not deliberately evaluate what kind of behavior is appropriate for men and women in every situation. Rather, deeply held subconscious models of gender automatically influence action (Vaisey 2009). Even when individuals do not themselves agree that existing normative standards are beneficial, they remain influenced by the expectations and standards of others around them (Milkie 1999).

Scholars who doubt the potential for gender non-conforming behavior to affect the gender system have theoretical roots in the early interactionist work on the sociology of gender, which upholds that the gender system is produced and reproduced through social interaction. West and 
Zimmerman (1987) contend that interactions between men and women, even those that appear to transgress the stasis of assigned gender roles, serve to reify difference, thereby maintaining gender hierarchy. Indeed, empirical studies from many domains of social life have documented how the incorporation of women into male-dominated spheres is accompanied by an emphasis on gender difference, and therefore does little to challenge the gender system (Deutsch 2007). For example, Pini (2005) documents how female agricultural workers enacted aspects of conventional masculinity (such as using farm machinery) while simultaneously foregrounding the femininity and compassion that distinguished them from male counterparts.

Relatedly, a body of literature documents the ways in which women's unequal burden of housework serves to reconstruct the gender system within the household, even as women assume gender non-conforming roles in public spaces (Hochschild 1989; Brines 1994). Bittman et al. (2003) find that when married women in the U.S. and Australia earn more income than their male spouse, they tend to compensate for this "gender deviance" by doing more housework. Interpersonal interactions are thus used to reinforce the gender system in the face of structural changes that have given women greater earning potential or undermined men's ability to achieve a breadwinner status ideal (Legerski and Cornwall 2010). These studies raise questions about the extent to which genuine change can result from gender non-conforming behavior.

Other scholars are more encouraging about opportunities for systemic change through gender non-conforming social interactions (Deutsch 2007; Risman 2009). These theories are based on understanding gender as a social structure that shapes individuals and their actions, but is simultaneously shaped by individuals' actions (Giddens 1984). Behaviors are constrained—some choices are more likely than others - but they are not determined by the systems in which we live. 
Resultingly, when individuals act in gender non-conforming ways, they have the potential to reshape the gender system.

An important part of this theoretical framework is the notion that gender beliefs have both a horizontal dimension, specifying how men and women are different, and a hierarchical dimension that attributes different-and differently valued — competences to men and women (Ridgeway and Correll 2004). The horizontal and hierarchical dimensions of gender norms are mutually reinforcing because beliefs in gender differences at the horizontal level sustain and legitimate gender hierarchy (Chafetz 1990; Lorber 1994; Risman 2004). Theories about interaction as a site of change posit that routinely performing gender in non-conventional ways, diminishes the appearance of gender difference, which can facilitate systemic transformation by undermining the internalized norms that legitimate gender hierarchy (Deutsch 2007). This suggests that the reduction of gender difference in daily life, especially for highly gendered tasks such as housework and care work, can be transformational (Shows and Gerstel 2009; Chesley 2011). While not articulated in theoretical terms, the logics underpinning many gender sensitization programs are rooted in this framework.

Given that not all gender non-conforming behavior is revolutionary; however, scholars have called for research that examines the conditions under which interactional change affects normative conceptions of gender (Deutsch 2007). This study examines the microdynamics of a gender sensitization and intimate partner violence prevention program for men, which was premised on the logic that changed behavior can disrupt gender hierarchy. This case proved ripe for the exploration of these theoretical expectations because facilitators, as well as program participants, largely emphasized behavior changes in their quotidian practices as the key mechanism through which to foster equality and erode hierarchy. 


\section{CONTEXT}

We carried out this research in 14 communities in the North and South Kivu provinces of DRC in 2016. This region has been subject to periodic armed conflict for more than two decades, causing substantial disruptions and economic hardship in the lives of residents (Baaz and Stern 2008; Stearns 2012). The disruptions have affected gender relations and the division of responsibilities within the household. Social and legal norms dictate that a husband, as the head of the household, is responsible for taking important decisions for the family, performing especially heavy agricultural tasks, and providing cash income. Women are expected to care for children, perform housework, contribute labor to regular agricultural tasks, and conduct petty trade when possible (Kesmaecker-Wissing and Pagot 2015). The conflict has limited men's abilities to provide for their families and increased burdens on women to earn income. A recent study in North Kivu found that the majority of men report being the family's main source of income, whereas far fewer women reported that their male partner was the main source of income for the household. The report concludes that women contribute substantially to household welfare through work outside the home, but their contributions are downplayed because they threaten men's identity as providers (Slegh et al. 2014).

The same study documented a strong adherence to unequal gender norms among both men and women. In focus groups, participants expressed resistance to gender equality and worried that it increased conflict in households. In a representative survey, 54 percent of men and 64 percent of women responded that gender equality had "gone far enough already" (ibid).

The division of labor in households reflects this support for gender differentiation. Women are overwhelmingly responsible for household tasks. Less than 10 percent of women reported that their husbands participate in cooking, cleaning, or washing clothes. Men reported participation in 
child care and emphasized the importance of fatherhood, although women are generally responsible for daily caregiving. Intimate partner violence is strikingly common as a means used by men to maintain their status in the household. The nationally representative Demographic and Health Survey found that 37 percent of women had experienced physical or sexual violence at the hand of an intimate partner in the 12 months preceding the survey; 53 percent had ever experienced such violence in their lifetime (Ministry of Planning and Monitoring et al. 2014).

The program that formed the basis for this research was the International Rescue Committee's (IRC) “Engaging Men through Accountable Practice” (EMAP) Program. EMAP is part of one of IRC's largest and longest-running programs designed to increase women's access to and control over resources, and to address the root-causes of gender-based violence. Since 2002, IRC has been working with local organizations and health partners to provide comprehensive services to gender-based violence survivors. The program design is based on a pilot intervention implemented in Côte d'Ivoire in 2011, which suggested that engaging men could lead to more gender equitable behaviors (Hossain et al. 2014). EMAP was adapted to emphasize accountability to women's voices and begins with an 8-week curriculum for women to discuss their needs and desires, which are integrated into the subsequent curriculum for men. The women who participate in the women's discussion groups are not necessarily affiliated or married to the male participants.

EMAP participants were men who volunteered to take part in the program. Program facilitators used public events and social networks to recruit men to join. They requested that men commit to not using violence in their own homes throughout the duration of the program. Men were informed that there would be no compensation for participation. Presumably, this recruitment strategy would attract men who hold more gender egalitarian attitudes than the population average. However, a baseline survey of 1,600 eligible men who expressed interest in the program and their 
female partners indicated a very high level of intimate partner violence. Approximately half of the women reported experiencing physical or sexual violence at the hands of an intimate partner in the previous 12 months (IRC, unpublished). The survey similarly confirmed the rigidity of gender norms discussed above, including with respect to the division of household labor. Only four percent of women reported that their husband participated in cleaning the house, three percent contributed to fetching water, and three percent helped with washing clothes. We do not assume, therefore, that program participants held gender egalitarian views at the outset of the program.

Of the 1,600 men who participated in the IRC baseline survey, approximately 700 men across 15 villages were selected to participate in EMAP's curriculum. The curriculum was comprised of discussion groups for 16 weeks, from August 2016 to January 2017. The men met in groups of 10-25 once per week and were guided through activities and discussion by two IRCtrained facilitators from the area. Each session consisted of a review of discussions from the previous week, interactive activities, and opportunities to share experiences. As an example, an activity during the second weekly session asks men to collectively brainstorm what it means to "act like a man" and to "act like a woman." The facilitator then guides a group discussion about how these social expectations are limiting for both men and women, and reinforce notions of women's inferiority.

Program goals included promoting an understanding of violence against women, preventing violence through behavior change, shifting attitudes toward gender equality, and promoting gender equitable behavior in households. The program manual defines gender equality as, "When rights, responsibilities and opportunities will not depend on whether individuals are born male or female" (IRC 2014, 13). The first seven program sessions were about gender, power, and accountability to women. They included discussion of the differential socialization of women 
and men, gender roles, masculinity, types of power and privilege, as well as directions for creating personal action plans for change. These were followed by five sessions on violence, focusing on different types of violence against women and the consequences thereof. The final four sessions were about "being an ally to women and girls" through supporting survivors of violence, demonstrating healthy relationships, and encouraging change in the community.

\section{DATA AND METHODS}

Data for this study were collected in two phases and using a variety of qualitative research methods. The first phase consisted of a series of in-depth individual interviews conducted before the beginning of the program in the 14 EMAP villages. The interviews were conducted in local languages by male Congolese researchers who were trained in interview techniques, ethnographic research, and the goals of the research by the authors. In each EMAP village, interviews were conducted with eight individuals: two men who had volunteered to participate in EMAP, two men who had decided against participating, the two program facilitators who had been trained and were waiting to begin implementing EMAP, one local customary leader, and one local religious leader. These interviews were designed to probe gender attitudes prior to the EMAP program. We also sought to understand the depth of support for EMAP programming, as well as the context and characteristics of the villages in which we were working. Together, the first phase of research comprised more than 100 interviews.

The second phase of the research from August 2016 to January 2017 consisted of in-depth participant observation and other methods of qualitative data collection throughout the implementation of the EMAP program. The three most skilled researchers from the first phase of data collection were retained to carry out the longitudinal research. Each researcher was assigned two communities, each of which included two EMAP discussion groups. The researchers 
alternated weeks between their two communities, spending nearly all weekdays conducting ethnographic research. They endeavored to make themselves accepted members of the community. Research participants were treated as friends and were never paid for participation. At the end of every week, the local researchers would send detailed field notes and the lead researchers would read the notes and provide feedback, guidance, and follow-up questions. Embedding local researchers in the study communities enabled the use of a variety of qualitative and participatory methods of data collection that would not have been possible for the lead researchers to replicate (Watkins and Swidler 2009; Angotti and Sennott 2015; Schatz et al. 2015). Moreover, ethnographic methods were employed to avoid relying solely on individual reports of behavior in a research setting. Interview responses alone would have been problematic for two reasons. First, the community perceived the research assistants as associated with the program implementers, therefore raising concerns about social desirability bias in interviews resulting in exaggerated claims of program adherence. Second, as described in the theory of change above, transformational change to the gender system that stems from interactional-level changes depends on gender nonconforming behavior triggering a social and communal process of re-evaluation of gender norms. For that reason, we wanted to observe "situated action" and processes of meaning making in everyday social interactions (Jerolmack and Khan 2014).

The first data collection activity in phase two was the observation of as many of the men's discussion group meetings as possible. The researchers were instructed to be silent observers and not to participate. As regular attendees, however, their presence became accepted as part of the social dynamic of the group and they did interact with participants and facilitators before and after the meetings. The researchers were better educated and more urban than the majority of the EMAP participants, but otherwise they shared many characteristics with the men in the program. During 
each discussion session, they took extended pen-and-paper notes on the topics of discussion, strategies used by facilitators to communicate EMAP ideas, common sources of agreement and disagreement, and testimonies from the participants' own lives.

As a second mode of data collection, the researchers observed and participated in informal conversations with groups of men, including EMAP participants as well as other inhabitants of the village. The researchers sought to become a regular and trusted presence in the villages, frequenting spaces where villagers gathered, such as ligalas (bars/drinking houses) and churches. They also observed informal conversations among groups of men subsequent to the conclusion of each EMAP session.

The third data collection activity involved closely following twelve EMAP participants throughout the duration of the EMAP intervention. We randomly selected one married participant between the ages of 25 and 40 from each discussion group for this activity. The researchers endeavored to spend one full day every fortnight with the participants selected for extended observation. This was so that they could become familiar with the way they lived with their families, as well as the ways in which they incorporated - or not - the principles of EMAP into their daily lives. The intent was to capture the process of change within participant households. This was also the activity that most facilitated the researchers' access to data from women who may have been affected by the EMAP program.

These data were supplemented with regular interviews with the EMAP facilitators. The researchers sought to identify the facilitators' role and reputation within the village, and the visibility of the facilitators' own engagement with EMAP principles. Additionally, the researchers examined the reactions of the facilitators toward the material conveyed in the EMAP curriculum, and their strategies for communicating with program participants. They investigated which aspects 
of EMAP's messages the facilitators felt were most readily embraced by program participants and why, as well as which messages inspired resistance.

Fifth and finally, the researchers used their observations of the discussion groups to identify participants with whom to conduct targeted interviews. They spoke with participants who expressed sustained resistance to the ideas of EMAP throughout the program. They also identified participants who seemed eager to incorporate EMAP principles into their daily lives. Last, they met with participants who offered testimonies of positive change, but for whom the researchers retained some skepticism regarding the sincerity of the participants' commitment. These interviews provided an opportunity to examine the relationship between participants' publicly and privately articulated beliefs or descriptions of their behaviors.

The research team conducted several forms of data analysis. First, after reading through interview transcripts from the first phase of the research, a purposive selection of transcripts was systematically coded using thematic codes developed from the initial research questions. After each author had coded some transcripts, we used research team discussions to interrogate emerging themes and to deliberate how to categorize complex passages in the transcripts. This part of the analysis informed the design and content of the second phase of the research. Since reactions to the EMAP program are the main focus of this paper, data from the initial interviews prior to the program enhance our understanding of the context but are not the primary source of evidence for the analysis.

Analysis of the notes from the longitudinal data collection proceeded in multiple phases and formed the main evidence base for the findings presented below. As a first step, the lead researchers examined the field notes transmitted by the research assistants on a weekly basis. This analysis was used to provide feedback and further instruction to the field researchers, and to 
develop supplementary data collection activities. Midway through the ethnographic data collection, one of the lead researchers conducted a two-day interim analysis workshop with the research assistants during which they discussed both the methods and initial findings of the research. Finally, toward the end of the data collection period, the research assistants took a oneweek break from data collection to review what they had learned and to respond to a series of analysis question prompts developed by the lead researchers. These included questions around which norms men appeared more or less amenable to changing and why; who seemed most willing to enact changes in the division of labor in their home; and community perceptions of the program. The research assistants were also asked to provide comprehensive profiles of the EMAP participants they had been following closely, the facilitators in their sites, and the men's discussion group dynamics. A final stage of analysis consisted of the lead researchers re-reading the data collection notes alongside the analysis memos provided by the research assistants and collectively deliberating the findings.

\section{FINDINGS}

Our research revealed patterns that advance our understanding of the conditions under which changes at the level of interaction can result in a broader, and transformational, challenge to the gender system. First, we show that the changes encouraged by EMAP - particularly among the most committed of participants - resulted in men's increased involvement in tasks usually performed by women. EMAP clearly inspired program participants to perform gender nonconforming behavior in the household, and provoked meaningful changes in daily life that could result in some labor relief to the partners of many program participants. Second, however, the research revealed that changes in the gendered division of labor in the household did little to undermine the core ideas that sustain gender hierarchy. In social interactions, when participants 
publicly reflected on the meaning of their behavior change, they emphasized their continued control in the household. Their narratives stressed that changes in quotidian practices should only be enacted on men's terms, which ultimately served to reinforce men's power.

\section{Quotidian Practice and Evidence of Behavior Change}

As EMAP progressed, it became evident that men were open to challenging the idea that there were specific tasks reserved for men and women. Many demonstrated genuine commitment to working toward greater equality in the division of household labor and relieving the domestic burdens placed on women. At the closing ceremony concluding the program in one of the communities, a community leader commented “men now understand that gendered tasks don't exist" (Community leader, Community 3, Fieldnotes 01/12/2017). ${ }^{1}$

Participants, program facilitators, and research assistants frequently described scenarios in which men were observed as they assisted with household labor, sweeping the house and terrace, fetching water, preparing food, and taking care of the children. One researcher recounted typical changes he observed in a participant's household:

When her husband arrived home, the woman did not have enough water.

I observed her husband take two cans of 20 liters each, and leave to fetch water for his wife. The tap was in a neighboring plot, approximately 20 meters away, and it appeared that they had been communicating regularly about this, since it seemed natural to both of them that the husband should exit to fetch the water. After that, he played with his twoyear-old daughter and took her to bed, while his wife was busy. (Participant Observation, Community 4, Fieldnotes, 09/30/2016). 
In another example, an EMAP facilitator visited the home of a participant of about 37 years and encouraged the man to take pride in his contributions to household labor. The fieldnotes describe that the participant had begun to perform some household tasks that had been the domain of his wife, notably cooking and childcare, but was hesitating to fetch water because he did not want to be seen in public performing "women's work." The fieldnotes summarize the facilitator's visit as he explained it to the researcher:

The facilitator arrived at [the participant's] home to visit his wife who was ill. When he arrived, he found the husband preparing fish to eat with the foufou. As soon as he finished, he served the children their food and left some for his wife who was in bed, so that they could eat together. At around $8 \mathrm{pm}$ he told the children to go to sleep and he soothed the 6-month old baby. When the facilitator passed by [the participant's home] again at 5:30 in the morning on his way to morning prayer, he found the man drawing water with two cans in hand. The facilitator noted that it was too early in the morning, and [the participant] replied that [fetching water] is the activity for which he feels the most shame, so he does it every morning, early, before people wake up. Instead of going to prayer, the facilitator stayed with him. They waited until people were already going about their business at about 7:00 am, and then the facilitator asked the participant to fetch two more cans of water. The participant resisted a bit, not wanting to make the facilitator work, but the facilitator insisted. They both went to the spring and came back with their cans full of water, while people were already in circulation. At home, the facilitator asked the participant what he feared by being seen by the passers-by. The facilitator told him that whenever he performed a task in the service of his home, he should feel very 
proud. The participant nodded his head, noting that these teachings needed to spread to many men (Facilitator Interview, Community 4, Fieldnotes, 10/14/2016).

In addition to increasing their participation in household tasks, men also began participating in agricultural tasks typically performed by women. This is a consequential change because agriculture is the main source of livelihood in these communities. During a discussion group meeting, one participant observed that he saw another member of the group weeding the beans with his wife, despite provoking astonishment from passers-by because beans are usually grown exclusively by women and weeding is a task typically performed by women alone (EMAP Discussion Group, Community 1, Fieldnotes, 09/23/2016). Another reported significant changes in the behavior of his co-participant, observing him planting sweet potatoes, an activity usually performed by women (EMAP Neighbor, Community 1, Fieldnotes, 09/23/2016).

Many women expressed gratitude for the changes they observed in their husbands. An EMAP facilitator, for example, recounted his observation of the home of a 30-year old program participant and noted substantial changes in the division of labor from his observations before the program:

When the facilitator arrived at the home, the wife had gone to the mill to grind the flour. As it was already evening, the husband was washing the children. When he finished washing the children, he began preparing vegetables, and the facilitator helped him. His wife arrived home to find the vegetables already cooking. When she saw this, she showed a sign of contentment and told her husband "koko mwira wani" to say, "thank you, my friend". The husband told her instead to say thank you to the facilitator who had introduced this new way of living. (EMAP Participant, Community 4, Fieldnotes, 10/14/2016) 
Testimonies of change reported by program participants thus suggested genuine engagement and implementation of new quotidian practices. The examples provided are a few among many. As the program progressed, men professed to welcome these changes, and appeared proud to acknowledge how their earlier behavior had disempowered and disrespected their wives. Indeed, as men were willing to perform tasks typically expected to be completed by women, it is evident that changes promoted by EMAP have the potential to ease the labor burdens placed on women. Yet, as described in the following section, participants ultimately undermined the transformative potential of these behavior changes to affect the broader architecture of the gender system.

\section{Sustaining Hierarchy: Determining the Objective, Process, and Meaning of Change}

Below, we present evidence of the ways in which gender hierarchy was reinforced by men's insistence on retaining control over the objective (end goal), process (which changes were enacted when), and meaning (shared vs. gendered responsibility) of change.

\section{i. $\quad$ The Objective of Change: Competing Conceptions of Gender Equality}

We define the objective of change as the desired end goal of the EMAP-promoted behavior change. Our research revealed an important difference between the definition of gender equality as envisaged by EMAP architects, and the definition of gender equality as interpreted by EMAP participants. Whereas the EMAP curriculum promotes a conceptualization of equality based on the erosion of gender hierarchy and unequal power relations, EMAP participants tended to understand and apply gender equality more narrowly as the equitable division of quotidian tasks.

At the outset, EMAP participants and facilitators acknowledged that men and women had different rights and responsibilities within society. As the program progressed, participants agreed 
that this could change. Participants understood the end goal of the change in one of two ways: 1) a fairer division of labor with complementarity between men and women's tasks and a willingness to help each other, or 2) the erosion of distinctions between men's work and women's work altogether. In other words, participants became increasingly committed to the idea that labor could be more equally shared between men and women, or, for the more progressive participants, that the gendered division of tasks could be collapsed altogether (Fieldnotes, 01/12/2017). The pressing need to share tasks more evenly was intended to relieve the time and labor burden for women.

The possibility of eliminating gender hierarchy, on the other hand, provoked strong resistance. As one participant noted, allowing women to be leaders in the household would "destabilize our social cohesion and contribute to the disintegration of the household" (EMAP Participant, Community 4, Fieldnotes, 08/29/2016). In a discussion about power during the discussion group meeting - comparing the concepts of power over versus power with-one participant noted his trepidation:

When using power with, one must be intelligent because if you do it wrong, my friends, the women will walk on the heads of men (EMAP Participant, Community 6, 11/28/2016).

It was typical for resistant statements to invoke fear that the erosion of hierarchy would inevitably lead to the oppression of men. There was a commonly held belief that women should not be made to feel so equal that they felt entitled to give orders. A participant in a baseline interview from a community not included in the longitudinal study summarized this sentiment:

I embrace equality, but a woman can never give the orders - that's not right (EMAP Participant, Baseline Site 17, Interview, 5/11/2016) 
EMAP participants thus accepted the need to share the labor burden more equally, but they generally did not agree that the goal of social change should be sharing responsibility, and thus sharing power. An intense exchange between a 60-year old pastor and the EMAP facilitator illustrates this resistance. When the facilitator attempted to assert that the house is not for the man alone, but rather it belongs to all members, the participant raised his voice to argue. He said, "All the EMAP teachings are ok, but on the question of how to refer to the household, we are not in agreement." The facilitator asked why only the man's name is used to refer to the household. The participant responded, "because he is the one responsible for the household." The researcher noted that the facilitator did not manage to resolve this disagreement because the participants all "resisted the notion that the wife could share the household title with her husband" (EMAP participants, Community 5, 11/4/2016).

\section{ii. $\quad$ The Process of Change: On His Terms}

Men's control over the process of change was demonstrated in their determination to retain control over which changes were made in the household and when. Even the most EMAP-supportive participants were resistant to enabling a dynamic that would permit their wives to hold them accountable for participating, or not participating, in household duties. This was a recurring theme across the research sites as men insisted that their partners should not be consulted when deciding when and how they would contribute to household tasks because it challenged the premise of social order.

The facilitator in Community 3 explained to the researcher that in almost all of the groups he facilitated: 
The practice that is very difficult for the participants to incorporate is to discuss the division of labor with their wives every day (Community 3, Facilitator Interview, 11/4/2016).

In Community 4, during an interview with an EMAP participant, the latter explained that the men did not discuss change with their wives because:

We told ourselves that if we talked about what the men were going to do, women would start to make orders to execute them (EMAP Participant, Community 4, Interview, 12/19/2016).

In an interview, one of the facilitators recounted a conversation from his group where he had explicitly asked the men why they do not want to talk to their wives about the changes they were making. The participants responded that it would create misunderstandings later. It would be unwise, they said, because: "it might come to the point that the woman will begin to reproach the man for not having done what was his." The group concluded that it was best for the man to simply enact these changes without first discussing them with his partner (EMAP Facilitator, Community 3, Interview, 09/23/2016). This indicates an explicit resistance among some of the men to the very idea of being held accountable by their partners or of setting expectations for any future or consistent contribution to household tasks.

The fieldnotes from the Community 3 closing ceremonies document the persistence of this sentiment. During the ceremony, a participant who had regularly attended the discussion groups and was generally supportive of the ideas introduced by EMAP, recommended that IRC sensitize women: 
So that they do not take advantage of their husbands by starting to make orders in the household as though they become the boss, otherwise that will lead men to resort to their old way of life (EMAP Participant, Community 3 Fieldnotes, 01/20/2017).

The research assistant noted that, while he was speaking, all the men in the room smiled, and some "even encouraged him by quietly commenting in the local language: 'Ciderhere Mushamuka,' meaning 'speak my brother'.” In the same ceremony, another stated that:

It is for this reason we shouldn't discuss with our wives the changes that the man has decided to implement in his life, but rather, [the women] should simply notice the changes themselves (ibid).

Changed household routines may signify the promise of some broader change, especially given the highly gendered division of tasks that preceded the program. However, by excluding their partners from the process of achieving more gender equal interactions in the household, men ensured that the hierarchical dimension of the gender system was preserved.

\section{iii. $\quad$ The Meaning of Change: Shared Responsibility vs. Men Helping in the House}

EMAP participants also retained authority over ascribing meaning to the changes they were enacting. Rather than assuming equal responsibility over household tasks, men continued to construe their contributions to household labor as "help" or "assistance," thereby reaffirming women's ultimate responsibility for these duties.

Exemplifying this language, a participant stated that what was valuable about EMAP was "learning to love his wife and help her in [her] tasks" (EMAP Participant, Community 4, Interview, 12/19/2016). Another stated that through EMAP he learned to: 
Show his wife that she is a human being like us men, which is the reason why men have to help their wives in domestic tasks, like fetching vegetables and helping women bring them back to the house to prepare them" (EMAP Participant, Community 6, Interview, $12 / 14 / 2016)$.

Many participants expressed commitment to assisting their wives only under the condition that she was in need of the assistance. For instance, help could be extended on the condition that she was already occupied, unwell, or otherwise unable to complete her tasks. Such sentiments were especially prevalent in the baseline data, collected before the program's implementation. But many men, even those enthusiastic about EMAP's goals, continued to hold such beliefs throughout the program. When asked in the closing ceremony for Community 2 what it means for a man to love his wife, participants responded:

A man who loves his wife only has to buy her food to eat and clothes. For domestic activities, men can only do these when his wife is away from the house or if she is unwell and hasn't found a girl who can help her (EMAP Participants, Community 2, Fieldnotes, 01/20/2017).

As such, participation in household tasks was typically construed as 'assisting' women with domestic duties that were still hers, rather than reflecting a sense of shared responsibility. Participants were thus able to ascribe a limited meaning to their new practices in the household, a meaning which, rather than signaling a fundamental shift, ultimately reaffirmed existing gender norms. 


\section{CONCLUSION}

Programs that engage men in efforts to reduce inequality seek to undermine support for gender hierarchy and inspire changes in the gendered division of tasks that underpin that hierarchy. Such programs thus offer a clear opportunity to examine prospects for 'undoing gender' at the level of interactions.

Our research revealed significant changes at the interactional level between men and women, namely changes in quotidian practices and the erosion, in some cases, of the strict gendering of tasks and behaviors. The significance of these changes should not be understated. It is clear that many men embraced aspects of the program, and made meaningful, if inconsistent, changes in their daily routines. Changes in the assignment of household and agricultural tasks are potentially consequential for women, who may benefit from a reduced labor burden.

What does this change at the interactional level mean for the gender system? Men's performance of more housework is an instance of gender non-conforming behavior in a domain where gender norms are expected to be especially salient (Ridgeway and Correll 2004). Men doing "women's work" can contribute to a reduction in perceived gender difference. Theories about interaction as a site of change posit that modifications to the performance of gender in daily interactions may lead to systemic transformation by inspiring shifts in gender norms. This study responds to calls for more research on the conditions under which interactional change affects normative conceptions of gender (Deutsch 2007,120).

Our data show that behavior changes that reduce gender difference can serve to reproduce rather than undermine aspects of the gender system, at least in the short-term. Even the most dedicated of EMAP participants preserved a commitment to gender hierarchy, and were unwilling to embrace the idea of equality as it was envisioned by EMAP architects. Importantly, in public 
settings, participants explicitly undermined attempts to link the reduction of gender difference in their daily lives with changes in norms about gender hierarchy.

The interpretation of men's public statements about the meaning of their behavior change is not immediately obvious. On the one hand, in the context of the program, there was social pressure to appear fully committed to gender equality. In individual interviews with the research assistants, affinity for the EMAP program and/or desire for continued community support from IRC were likely salient contextual factors affecting reports of behaviors and attitudes (Jerolmack and Khan 2014). Given that lens, participants' open rejections of equality as shared power offer strong evidence that the observed behavior changes will not lead to transformational change.

On the other hand, EMAP participants likely expect other community members to evaluate their behaviors in light of prevailing gender norms that emphasize gender difference and hierarchy. Social psychology research shows that individuals are affected indirectly by other people's images of success because they believe that others will evaluate them according to that image (Milkie 1999). EMAP participants' talk about how their behavior change is consistent with the fundamental principles of established norms may be a way of protecting themselves against social sanctions. It may be face-saving talk, rather than evidence of true disbelief. Furthermore, while the program was designed to encourage critical examination and discussion of taken-for-granted ideas about gender, it is still true that gender beliefs are deeply held and therefore slow to change. Even if participants' ideas about gender relations have begun to shift, they may not know how to articulate their new beliefs in ways that make sense to themselves and their community members. In public interactions, therefore, it is understandable that program participants appeal to prevailing gender norms of difference and hierarchy when ascribing meaning to their behavior changes. 
While the data gathered in this study are insufficient to tell us how participants adjudicated between these competing social pressures, what we do know is that their public statements reinforced commonly held beliefs in men's hierarchical superiority. Interactional-level changes are hypothesized to lead to systemic change by inspiring a social process through which the norms that define men and women as different and unequal are reconsidered. In this case, we see men explicitly undermining that social process. EMAP participants' public assertions steer the collective away from a move toward greater gender equality. Their public speech is a social action that undermines the transformative potential of their relatively egalitarian behavior.

The timeframe of this study poses one important limitation on the conclusions that can be drawn. The data were collected during the implementation of the behavior change program. The changes observed were relatively new, and EMAP participants, their families, and their communities had not had much time to evaluate the meaning and consequences of men's greater participation in "women's work." It is logical that men's initial attempts to make sense of their changed behavior appealed to existing norms of gender hierarchy. If their behavior changes are sustained over the long-term, however, it is possible that a lasting reduction of gender difference in the performance of quotidian tasks could lead to shifts in norms about gender hierarchy. Over time, it is conceivable that a reduction in gender differences in the division of labor may lead men to develop a better understanding of women's lived realities, and the detrimental effects of the gender hierarchy for both men and women. The findings presented above suggest that the likelihood of those types of normative shifts in the long-term would be enhanced if men become willing to share power and responsibilities with their wives, in addition to sharing the labor. The long-term consequences of the observed behavior changes cannot be gleaned from the data currently available. That said, what we have learned from this empirical study of the short-term 
impact of interactional-level changes provides important insight into the conditions that are likely to facilitate or constrain transformation over any timeframe.

Our data suggests that whether gender can be "undone" through interaction depends on how power is distributed within those interactions and the microdynamics surrounding them. Power-sharing was central to the initial conceptualization of EMAP, which intended to promote the idea that men should be accountable to women in their community. Ultimately, while men were willing to embrace an idea of equality premised on behavior changes, the notion of being equal or accountable to women in any broader sense evoked strong public resistance. While interactional changes that are rooted in genuine accountability might offer a more credible threat to gender-unequal power, the performance of gender non-conforming behaviors alone does little to upend the gender system. Indeed, without seriously incorporating women into the objective, process, and meaning of change, even fairly significant interactional changes only serve to reproduce gender inequality by preserving male dominance. 


\section{NOTES}

1. All quotes are referenced using the individual's position in the community (e.g., participant, facilitator, non-participant, etc.); the community; the data source (e.g., interviews, fieldnotes, etc.); and the date. Other identifying information has been removed to protect participant confidentiality. 


\section{REFERENCES}

Angotti, Nicole and Christie Sennott. 2015. Implementing 'insider' ethnography: Lessons from Public Conversations about HIV/AIDS project in rural South Africa. Qualitative Research 15(4): 437-453.

Baaz, Maria Eriksson, and Maria Stern. 2011. Whores, men, and other misfits: Undoing feminization in the armed forces in the DRC. African Affairs 110 (441): 563-85.

Barker, Gary et al. 2010. Questioning gender norms with men to improve health outcomes: Evidence of impact. Global Public Health 5(5): 539-553.

Bittman, Michael, Paula England, Liana Sayer, Nancy Folbre, and George Matheson. 2003. When does gender trump money? Bargaining and time in household work. American Journal of Sociology 109(1): 186-214.

Brines, Julie. 1994. Economic dependency, gender, and the division of labor at home. American Journal of Sociology 100 (3): 652-688.

Butler, Judith. 1990. Gender trouble: Feminism and the subversion of identity. New York: Routledge.

Chafetz, Janet Saltzman. 1990. Gender equity: An integrated theory of stability and change. Newbury Park, CA: Sage Publications.

Chesley, Noelle. 2011. Stay-at-home fathers and breadwinning mothers: Gender, couple dynamics, and social change. Gender \& Society 25(5):642-664.

Deutsch, Francine M. 2007. Undoing gender. Gender \& Society 21 (1): 106-127.

Giddens, Anthony. 1984. The constitution of society: Outline of the theory of structuration. Berkeley: University of California Press. 
Hochschild, Arlie Russell. 1989. The second shift. New York: Penguin Books.

Hossain, Mazeda, Cathy Zimmerman, Ligia Kiss, Tanya Abramsky, Drissa Kone, Monika Bakayoko-Topolska, Jeannie Annan, Heidi Lehmann, and Charlotte Watts. 2014. Working with men to prevent intimate partner violence in a conflict-affected setting: A pilot cluster randomized controlled trial in rural Côte d'Ivoire. BMC Public Health 14: 339. doi:10.1186/1471-2458-14-339.

International Rescue Committee. 2014. Implementation guide: preventing violence against women and girls: Engaging men through accountable practice. New York: International Rescue Committee.

Jerolmack, Colin and Shamus Khan. 2014. Talk is cheap: Ethnography and the attitudinal fallacy. Sociological Methods \& Research 43(2):178-209.

Kesmaecker-Wissing, Melanie and Anais Pagot. 2015. Driven apart: How repeated displacement changes family dynamics in Eastern DRC. Geneva, Switzerland: The Internal Displacement Monitoring Center, Norwegian Refugee Council.

Legerski, Elizabeth Miklya and Marie Cornwall. 2010. Working-class job loss, gender, and the negotiation of household labor. Gender \& Society 24(4):447-474.

Lorber, Judith. 1994. Paradoxes of gender. New Haven, CT: Yale University Press.

Milkie, Melissa A. 1999. Social comparisons, reflected appraisals, and mass media: The impact of pervasive beauty images on black and white girls' self-concepts. Social Psychology Quarterly 62(2):190-210.

Ministry of Planning and Monitoring of the Realization of the Modernity Revolution (MPSMRM), Ministry of Health (MSP), and ICF International, 2014. Enquête démographique et de 
santé en République Démocratique du Congo 2013-2014. Rockville, Maryland, USA : MPSMRM, MSP et ICF International.

Pini, Barbara 2005. Farm women: Driving tractors and negotiating gender. International Journal of Sociology of Agriculture and Food, 13(1): 1-18.

Ridgeway, Cecilia L. and Shelley J. Correll. 2004. Unpacking the gender system: A theoretical perspective on gender beliefs and social relations. Gender \& Society 18(4): 510-531.

Ridgeway, Cecilia L. 2009. Framed before we know it: How gender shapes social relations. Gender \& Society 23(2): 145-160.

Risman, Barbara J. 2004. Gender as a social structure: Theory wrestling with activism. Gender \& Society 18(4): 429-450.

Risman, Barbara J. 2009. From doing to undoing: Gender as we know it. Gender \& Society 23(1): $81-84$.

Schatz, Enid, Nicole Angotti, Sangeetha Madhavan, and Christie Sennott. 2015. Working with a team of 'insiders': Qualitative approaches to data collection in the global south. Demographic Research 32: 369-396.

Shows, Carla and Naomi Gerstel. 2009. Fathering, class, and gender: A comparison of physicians and emergency medical technicians. Gender \& Society 23(2):161-187.

Slegh, Henny et al. 2014. Gender relations, sexual and gender-based violence and the effects of conflict on women and men in North Kivu, Eastern Democratic Republic of the Congo: Results from the International Men and Gender Equality Survey (IMAGES). Washington, DC and Capetown, South Africa: Promundo-US and Sonke Gender Justice.

Stearns, Jason K. 2012. Dancing in the glory of monsters: The collapse of the Congo and the Great War of Africa. New York: PublicAffairs. 
Sullivan, Oriel. 2004. Changing gender practices within the household: A theoretical perspective. Gender \& Society 18(2): 207-222.

Vaisey, Stephen. 2009. Motivation and justification: A dual-process model of culture in action. American Journal of Sociology 114(6):1675-1715.

Watkins, Susan Cotts and Ann Swidler. 2009. Hearsay ethnography: Conversational journals as a method for studying culture in action. Poetics 37: 162-184.

West, Candace, and Don Zimmerman. 1987. Doing gender. Gender \& Society 1(2): 125-51. doi:10.1177/0891243287001002002. 